\title{
SOME NEW NONLINEAR WEAKLY SINGULAR INTEGRAL INEQUALITIES AND THEIR APPLICATIONS
}

\begin{abstract}
RUN XU
Abstract. The purpose of the present note is to establish some new weakly singular integral inequalities of Wendroff type, which generalized some known weakly singular inequalities for functions in two variables. The inequalities given here can be used in the analysis of various problems in the theory of certain classes of integral equations and evolution equations.
\end{abstract}

Mathematics subject classification (2010): 42B20, 26D07, 26D15.

Keywords and phrases: Integral inequality, weakly singular kernel, nonlinear.

\section{REFERENCES}

[1] E. F. Beckenbach And R. Bellman, Inequalities, Ergebnisse der Mathematik und ihrer Grenzgebiete, Springer, Berlin, Germany, 1961.

[2] V. Lakshmikantham and S. Leela, Differential and Integral Inequalities: Theory and Applications, vol. I: Ordinary Dfferential Equations, Mathematics in Science and Engineering, Academic Press, New York, NY, USA, 1969.

[3] V. Lakshmikantham and S. Leela, Differential and Integral Inequalities: Theory and Applications, vol. II: Functional, Partial, Abstract, and Complex Differential Equations, Mathematics in Science and Engineering, Academic Press, New York, NY, USA, 1969.

[4] D. BANOV AND P. Simeonov, Integral Inequalities and Applications, vol. 57 of Mathematics and Its Applications, Kluwer Academic Publishers, Dordrecht, The Netherlands, 1992.

[5] R. P. AgARwal, Difference Equations and Inequalities, Marcel Dekker, New York, NY, USA, 1993.

[6] B. G. PACHPATTE, Inequalities for Differential and Integral Equations, vol. 197 of Mathematics in Science and Engineering, Academic Press, San Diego, Calif, USA, 1998.

[7] D. Henry, Geometric Theory of Semilinear Parabolic Equations, vol. 840 of Lecture Notes in Mathematics, Springer, Berlin, Germany, 1981.

[8] F. C. JiAnG, F. W. MENG, Explicit bounds on some new nonlinear integral inequalities with delay, J. Comput. Appl. Math. 205 (2007) 479-486.

[9] Q. H. MA AND E. H. YANG, Estimates on solutions of some weakly singular Volterra integral inequalities, Acta Mathematicae Applicatae Sinica, vol. 25, no. 3, pp. 505-515, 2002.

[10] Q. H. MA AND J. PEČARIĆ, Some new explicit bounds for weakly singular integral inequalities with applications to fractional differential and integral equations, Journal of Mathematical Analysis and Applications, vol. 341, no. 2, pp. 894-905, 2008.

[11] Run Xu, FAnwei Meng, Some new weakly singular integral inequalities and their applications to fractional differential equations, Journal of Inequalities and Applications 2016 (1), 1-16.

[12] W. S. Cheung, On some new integral differential inequalities of the Gronwall and Wendroff type, Journal of Mathematical Analysis and Applications, vol. 178, no. 2, pp. 438-449, 1993.

[13] A. P. Prudnikov, Yu. A. Brychkov, And O. I. Marichev, Integrals and Series, Elementary Functions, vol. 1, "Nauka", Moscow, Russia, 1981.

[14] Run Xu, Fanwei Meng, Cuinua Song, On Some Integral Inequalities on Time Scales and Their Applications, Journal of Inequalities and Applications, Volume 2010, Article ID 464976, 1-13.

[15] RUN XU, YING ZHANG, Generalized Gronwall fractional summation inequalities and their applications, Journal of Inequalities and Applications, (2015) 2015:242. 
[16] Zhaowen Zheng, Xin Gao And Jing Shao, Some new generalized retarded inequalities for discontinuous functions and their applications, Journal of Inequalities and Applications, 2016 (1), 1-14, doi 10.1186/s13660-015-0943-6. 